\title{
Hubungan Kejadian Plasenta Previa dengan Riwayat Kehamilan Sebelumnya
}

\author{
Widia R. Husain, ${ }^{1}$ Freddy Wagey, ${ }^{2}$ Eddy Suparman $^{2}$
}

\author{
${ }^{1}$ Program Studi Pendidikan Dokter Fakultas Kedokteran Universitas Sam Ratulangi Manado \\ ${ }^{2}$ Bagian Kebidanan dan Kandungan Fakultas Kedokteran Universitas Sam Ratulangi \\ Manado \\ Email: widiarhusain@yahoo.com
}

\begin{abstract}
To date, the main cause of maternal mortality rate is bleeding. Placenta previa is one of the causes of bleeding in pregnant women. This study was aimed to obtain the relationship between the occurence of placenta previa and pregnancy history among patients at RS Bhayangkara Manado, RSU GMIM Pancaran Kasih Manado, Prof. Dr. R. D. Kandou Hospital Manado. This was a descriptive and retrospective study with a cross sectional design. Subjects were pregnant women or women who laboured from January 2017 to December 2018 that had placenta previa. There were 72 cases as subjects, obtained by using non random sampling. The results showed that placenta previa were most common among subjects aged $\geq 35$ tahun as many as 30 subjects (41.7\%), multiparity as many as 39 subjects (54.2\%), no history of sectio caesarea as many 39 subjects (54.2\%), and no history of curetage as many as 66 subjects $(91.7 \%)$. In conclusion, there were relationships between the occurence of placenta previa and age $\geq 35$ years as well as multiparity, albeit, there were no relationships between the occurence of placenta previa and sectio caesaria as well as curetage history.

Keywords: placenta previa, age, parity, histories of sectio caesarea and curetage
\end{abstract}

\begin{abstract}
Abstrak: Penyebab angka kematian ibu (AKI) yang utama ialah perdarahan. Plasenta previa merupakan salah satu penyebab perdarahan yang tersering terjadi pada ibu hamil. Penelitian ini bertujuan untuk mengetahui hubungan kejadian plasenta previa dengan riwayat kehamilan sebelumnya di RS Bhayangkara Manado, RSU GMIM Pancaran Kasih Manado dan RSUP Prof. Dr. R. D. Kandou Manado. Jenis penelitian ialah deskriptif retrospektif dengan desain potong lintang. Subyek penelitian ialah ibu hamil atau bersalin yang mengalami plasenta previa pada periode Januari 2017-Desember 2018 yang berjumlah 72 kasus, diperoleh dengan metode non random sampling. Hasil penelitian menunjukkan kejadian plasenta previa terbanyak pada usia ibu $>35$ tahun yaitu 30 orang $(41,7 \%)$, paritas multipara yaitu 39 orang $(54,2 \%)$, tidak ada riwayat seksio sesarea yaitu 39 orang $(54,2 \%)$, dan tidak ada riwayat kuretase yaitu 66 orang $(91,7 \%)$. Simpulan penelitian ini ialah terdapat hubungan kejadian plasenta previa dengan usia ibu dan multiparitas namun tidak terdapat hubungan dengan riwayat seksio sesarea dan riwayat kuretase.
\end{abstract}

Kata kunci: plasenta previa, umur ibu, paritas, riwayat seksio sesaria dan riwayat kuretase

\section{PENDAHULUAN}

Berdasarkan data dari World Health Organization (WHO) angka kematian ibu sangat tinggi. Sekitar 830 wanita meninggal karena komplikasi kehamilan atau persalinan diseluruh dunia setiap harinya. Diperkirakan pada tahun 2015 sekitar
303.000 wanita meninggal selama dan setelah kehamilan dan persalinan. ${ }^{1}$

Di Indonesia, menurut Survei Demografi dan Kesehatan Indonesia (SDKI) tahun 2012, angka kematian ibu di Indonesia masih tinggi sebesar 359 per 100.000 kelahiran hidup. Berdasarkan data 
dari tahun 2010-2013 penyebab kematian terbesar kematian ibu ialah perdarahan. ${ }^{2}$ Kematian ibu di Indonesia umumnya disebabkan oleh perdarahan, eklampsi, komplikasi aborsi, partus macet dan sepsis. Perdarahan yang bertanggung jawab atas $28 \%$ kematian ibu sering tidak dapat diperkirakan. ${ }^{3}$

Perdarahan sebagai penyebab kematian ibu terdiri atas perdarahan antepartum dan perdarahan postpartum. Perdarahan antepartum merupakan kasus gawat darurat yang kejadiannya berkisar 3\% dari semua persalinan. Penyebabnya antara lain plasenta previa, solusio plasenta, dan vasa previa. ${ }^{4}$

Pada tahun 2011 di RSUP Prof Dr. R. D. Kandou Manado, dari 4155 kasus, terdapat dua penyebab utama perdarahan obstetrik yaitu 60 kasus $(1,44 \%)$ perdarahan antepartum dan 36 kasus $(0,86 \%)$ perdarahan postpartum sedangkan penyebab utama perdarahan antepartum ialah plasenta previa pada 59 kasus $(98,3 \%)$ dan retensio plasenta pada 10 kasus $(27,8 \%)$. Oleh karena itu, kemungkinan terjadinya plasenta previa pada perdarahan antepartum harus dipikirkan terlebih dahulu. ${ }^{5}$

Menurut data dari Kemenkes RI 2007, prevalensi plasenta previa di Indonesia pada tahun 2005 ialah $2,77 \%$ dan $0,85 \%$ di antaranya meninggal. ${ }^{6}$

Plasenta previa adalah komplikasi kehamilan dimana plasenta terletak di bagian bawah rahim, sebagian atau seluruhnya menutupi leher rahim. Hal ini menyebabkan perdarahan vagina tanpa rasa sakit dan beberapa mengarah ke perdarahan yang mungkin cukup besar untuk mengancam kehidupan ibu dan janin yang mengarahkan ke persalinan segera, baik secara elektif atau darurat. ${ }^{7}$

Plasenta previa disebabkan oleh implantasi blastokista yang terletak rendah dalam rongga rahim. Faktor-faktor yang memengaruhi terjadinya plasenta previa ialah meningkatnya paritas ibu, meningkatnya usia ibu, kehamilan ganda, tindakan kuratase, riwayat seksio sesarea sebelumnya, adanya bekas luka pada rahim dan miomektomi atau endometritis, riwayat plasenta previa, dan kebiasaan merokok. ${ }^{8}$
Ditemukan $80 \%$ dari kasus plasenta previa terjadi pada wanita yang multiparitas dan risikonya meningkat pada ibu hamil yang berusia $>35$ tahun. Usia kecil dari 20 tahun juga dinilai berisiko karena hipoplasia endometrium. Hal ini juga disebabkan endometrium belum siap menerima hasil konsepsi yang berdampak pada gangguan vascular dan selanjutnya terjadi plasenta previa. ${ }^{9-11}$

Berdasarkan latar belakang yang telah diuraikan, maka penulis tertarik untuk mengetahui sejauh mana hubungan antara plasenta previa dengan riwayat kehamilan sebelumnya seperti usia, paritas, riwayat seksio sesarea, dan riwayat kuretase pada kehamilan sebelumnya.

\section{METODE PENELITIAN}

Penelitian ini dilakukan di Bagian Obstetri dan Ginekologi di RSUP Prof. Dr. R. D. Kandou Manado, RS Bhayangkara Manado, dan RSU GMIM Pancaran Kasih Manado pada bulan September 2019November 2019. Jenis penelitian ini ialah deskriptif retrospektif dengan desain potong lintang.

Populasi penelitian ini ialah semua ibu hamil atau bersalin di RSUP Prof. Dr. R. D. Kandou Manado, RS Bhayangkara Manado dan RSU GMIM Pancaran Kasih Manado terhitung bulan Januari 2017 sampai Desember 2018 yang tercatan di rekam medis yaitu sebesar 8.328.

Teknik pengambilan sampel dalam penelitian ini dengan menggunakan teknik non random sampling atau purposive sampling. Sampel penelitian ini ialah semua anggota populasi yang memenuhi kriteria inklusi diambil sebagai subjek penelitian. Kriteria inklusi yaitu ibu yang melakukan persalinan dan didiagnosis plasenta previa, serta tercatat pada rekam medik rumah sakit tempat dilakukannya penelitian sebanyak 72 orang.

Variabel dalam penelitian ini terdiri dari plasenta previa, usia ibu, jumlah paritas, riwayat seksio sesarea, dan riwayat kuretase.

Penelitian ini telah mendapat persetujuan dari Komisi Etik Penelitian Kesehatan 
RSUP Prof. Dr. R. D. Kandou Manado, dengan nomor keterangan layak etik yaitu No. 047/EC/KEPK-KANDOU/X/2019.

\section{HASIL PENELITIAN}

Analisis uniavariat pada penelitian ini bertujuan untuk mengetahui distribusi frekuensi variabel yang diteliti, baik variabel dependen maupun independen. Pada penelitian ini didapatkan bahwa dari 72 kasus plasenta previa, frekuensi terbanyak pada usia $\geq 35$ tahun $(52,8 \%)$. Berdasarkan paritas, frekuensi terbanyak pada wanita dengan multipara yaitu 39 kasus $(54,2 \%)$. Berdasarkan riwayat seksio sesaria, frekuensi terbanyak ialah ibu yang tidak ditemukan riwayat seksio sesarea yaitu 39 kasus $(54,2 \%)$. Berdasarkan riwayat kuretase, frekuensi terbanyak ialah ibu yang tidak ditemukan riwayat kuretase yaitu 66 kasus $(91,7 \%)$.

Tabel 1 memperlihatkan dari 72 subyek yang mengalami plasenta previa, usia terbanyak mengalami kejadian plasenta previa ialah $\geq 35$ tahun pada 38 orang $(52,8)$.

Tabel 1. Distribusi subyek penelitian berdasarkan usia

\begin{tabular}{ccc}
\hline Usia (tahun) & N & \% \\
\hline $20-24$ & 10 & 13,9 \\
$25-29$ & 15 & 20,8 \\
$30-34$ & 9 & 12,5 \\
$\geq 35$ & 38 & 52,8 \\
Jumlah & 72 & 100 \\
\hline
\end{tabular}

Tabel 2 memperlihatkan dari 72 subyek yang mengalami plasenta previa, paritas terbanyak mengalami kejadian plasenta previa ialah multipara pada 39 orang $(54,2 \%)$.

Tabel 3 memperlihatkan bahwa dari 72 subyek yang mengalami plasenta previa terdapat 33 subyek $(45,8 \%)$ dengan riwayat seksio sesarea (SC) dan 39 subyek $(54,2 \%)$ tidak mempunyai riwayat SC.

Tabel 4 memperlihatkan bahwa dari jumlah 72 subyek yang mengalami plasenta previa terdapat 6 subyek $(8,3 \%)$ dengan riwayat kuretase dan mayoritas 66 subyek
$(91,7 \%)$ tidak mempunyai riwayat kuretase.

Tabel 2. Distribusi subyek penelitian berdasarkan paritas

\begin{tabular}{ccc}
\hline Paritas & N & \% \\
\hline Nulipara & 5 & 6,9 \\
Primipara & 28 & 38,9 \\
Multipara & 39 & 54,2 \\
Jumlah & 72 & $100 \%$ \\
\hline
\end{tabular}

Tabel 3. Distribusi subyek penelitian berdasarkan riwayat seksio sesarea (SC)

\begin{tabular}{ccc}
\hline Riwayat SC & $\mathbf{N}$ & $\mathbf{\%}$ \\
\hline Ya & 33 & 45,8 \\
Tidak & 39 & 54,2 \\
Jumlah & 72 & 100 \\
\hline
\end{tabular}

Tabel 4. Distribusi subyek penelitian berdasarkan riwayat kuretase

\begin{tabular}{ccc}
\hline $\begin{array}{c}\text { Riwayat } \\
\text { kuretase }\end{array}$ & $\mathbf{N}$ & $\mathbf{\%}$ \\
\hline Ya & 6 & 8,3 \\
Tidak & 66 & 91,7 \\
Jumlah & 72 & 100 \\
\hline
\end{tabular}

\section{BAHASAN}

Keseluruhan dari jumlah ibu hamil yang mengalami plasenta previa dengan usia risiko tinggi lebih besar dibandingkan ibu yang mengalami plasenta previa dengan usia risiko rendah. Hal ini disebabkan karena pada usia $<20$ tahun organ reproduksi wanita belum siap untuk menerima kehamilan, demikian juga dengan jaringan endometriumnya, sedangkan pada usia $>35$ tahun ibu hamil berisiko mengalami plasenta previa dikarenakan adanya penurunan fungsi fisiologis dan reproduksi secara umum. Lebih besarnya jumlah ibu hamil yang mengalami plasenta previa pada usia risiko tinggi dibandingkan dengan usia risiko rendah menandakan bahwa terdapat hubungan antara usia dengan kejadian plasenta previa. ${ }^{12,13}$

Hasil penelitian ini sejalan dengan pernyataan Manuaba ${ }^{10}$ yang menyebutkan bahwa ibu yang berisiko mengalami plasenta previa merupakan ibu dengan usia diatas 35 tahun karena terjadinya penurunan kualitas pertumbuhan dinding endo- 
metrium akibat sklerosis pembuluh darah arteri kecil dan arteriol miometrium yang menyebabkan aliran darah ke edometrium tidak merata sehingga endometrium menjadi kurang subur dan menyebabkan implantasi terjadi pada segmen bawah rahim. Demikian pula dengan ibu yang usianya lebih muda dengan pertumbuhan dinding endometrium yang belum sempurna.

Hasil penelitian ini sejalan dengan penelitian yang dilakukan oleh Metti $^{14}$ di RSUP Dr. Hi. Abdul Moeloek Provinsi Lampung, yang melaporkan bahwa dari 96 orang yang dijadikan sampel dominan usia dengan risiko tinggi $(<20$ atau $>35$ tahun) dapat mengalami plasenta previa dengan nilai $\mathrm{p}=0,018 \quad(<\alpha=0,05)$ sehingga dapat disimpulkan bahwa terdapat hubungan atara usia dengan kejadian plasenta previa.

Hasil penelitian ini juga selaras dengan penelitian yang dilakukan oleh Hartuti ${ }^{15}$ di RSUD Syech Yusuf Gowa yang menunjukkan hasil analisis chi-square dengan nilai $\mathrm{p}=0,015(<\alpha=0,05)$ yang berarti terdapat hubungan antara usia dengan kejadian plasenta previa.

Pada ibu dengan risiko tinggi atau multipara, makin tinggi paritas ibu maka semakin menurun kualitas endometrium. Hal ini diakibatkan oleh vaskularisasi yang berkurang ataupun perubahan atrofi pada desidua akibat persalinan yang lampau. Implantasi plasenta yang berulang pada daerah fundus dapat menyebabkan terjadinya plasenta previa karena aliran darah ke plasenta tidak cukup dan memperluas permukaannya untuk mencari bagian dengan pasokan darah yang banyak untuk memenuhi kebutuhan nutrisi dan oksigen begi janin yaitu bagian segmen bawah uterus dan menutupi jalan lahir. Lebih besarnya jumlah kejadian plasenta previa pada ibu dengan paritas tinggi atau multipara dibandingkan ibu dengan paritas rendah atau primipara menandakan adanya hubungan antara paritas dengan kejadian plasenta previa. $^{16}$

Hasil penelitian ini sejalan dengan penelitian yang telah dilakukan $\mathrm{Metti}^{14} \mathrm{di}$ RSUP Dr. Hi. Abdul Moeloek Provinsi Lampung yang menunjukkan hasil dari 20 orang ibu primipara sebanyak 2 orang (10\%) mengalami plasenta previa, sedangkan ibu multipara mengalami plasenta previa sebanyak 30 orang $(25,3 \%)$ dari 76 orang mengalami plasenta previa.

Penelitian ini juga sejalan dengan penelitian yang dilakukan oleh Hartuti ${ }^{15}$ di RSUD Syech Yusuf Gowa yang menunjukkan hasil analisis chi-square dengan nilai $\mathrm{p}=0,008 \quad(<\alpha=0,05)$ yang berarti terdapat hubungan antara paritas dengan kejadian plasenta previa. Selain itu, penelitian yang dilakukan oleh Junita ${ }^{16}$ di RSUD Rokan Hulu 2 mengenai hubungan paritas ibu dengan plasenta previa setelah dilakukan analisis uji chi-square memperoleh nilai $\mathrm{p}=0,0001 \quad(<\alpha=0,05)$ yang menunjukkan terdapat hubungan bermakna antara paritas dengan kejadian plasenta previa.

Riwayat seksio sesarea pada ibu di kehamilan sebelumnya bukan menjadi hal yang mutlak sebagai penyebab terjadinya plasenta previa di kehamilan berikutnya. Terdapat faktor lain yang dapat menyebabkan plasenta previa seperti usia ibu yang sudah lanjut, multiparitas, gemeli, hipoplasia endometrium, endometrium cacat, bekas aborsi, dan riwayat plasenta previa sebelumnya. Dengan demikian dapat dikatakan tidak terdapat hubungan bermakna dari kejadian plasenta previa dengan riwayat seksio sesarea pada kehamilan sebelumnya.

Mochtar ${ }^{11}$ menyatakan bila melahirkan janin dengan sayatan pada dinding uterus, sayatan inilah yang dapat mengakibatkan parut di dalam rahim sehingga meningkatkan kemungkinan terjadinya plasenta previa. Cunningham et $\mathrm{al}^{17}$ juga menyatakan kejadian plasenta previa akan meningkat pada wanita yang sudah dilakukan 2 kali atau lebih seksio sesarea. Penyebab terjadinya plasenta previa belum diketahui secara pasti, namun kerusakan endometrium pada persalinan sebelumnya dan gangguan vaskularisasi desidua dianggap sebagai mekanisme yang mungkin menjadi faktor penyebab terjadinya plasenta previa. Faktor kuatnya perlekatan plasenta disebabkan oleh adanya luka parut ada uterus 
akibat persalinan secara seksio sesarea, sering plasenta tertanam pada jaringan uterus dan desidua melapisi jaringan ini Jika jaringan parut bekas seksio sesarea mengakibatkan implantasi plasenta menjadi rendah pada ostium uteri internum maka hal ini akan meningkatkan risiko plasenta previa. Riwayat persalinan seksio sesarea akan meningkatkan risiko terjadinya plasenta previa yaitu 3,9\% lebih tinggi bila dibandingkan dengan angka 1,9\% untuk keseluruhan kejadian obstetrik. ${ }^{10}$

Riwayat kuretase tidak mutlak berpengaruh dengan kejadian plasenta previa. Hal ini juga dapat dipengaruhi oleh sebab lainnya yaitu usia, paritas, riwayat seksio sesarea, dan riwayat plasenta previa sebelumnya sehingga pada hasil penelitian ini tidak ditemukan hubungan plasenta previa dengan riwayat kuretase.

Penelitian ini juga sejalan dengan penelitian yang telah dilakukan di Fakultas Kedokteran, Rumah Sakit King Chulalongkorn Memorial, Universitas Chulalongkorn yang melaporkan bahwa riwayat operasi uterus sebelumnya ditemukan pada kelompok plasenta previa lebih banyak daripada kelompok kontrol tetapi pada uji statistik tidak ditemukan perbedaan bermakna. Riwayat seksio sesaria $(18,9 \%$ vs $16,5 \%$, $\mathrm{p}=0,6)$, riwayat miomektomi sebelumnya $(1,5 \%$ vs $0 \%, p=0,1)$, serta dilatasi dan kuretase sebelumnya $(17,5 \%$ vs $11,2 \%$, $\mathrm{p}=0,1)$. Odds ratio dari seksio sesarea sebelumnya dan dilatasi serta kuretase sebelumnya untuk plasenta previa ialah masing-masing 1,2 (95\% CI 0,7 - 1,9) dan 1,7 (95\% CI 0,9 - 2,9), masing-masing. ${ }^{18}$

\section{SIMPULAN}

Terdapat hubungan antara kejadian plasenta previa dengan riwayat kehamilan sebelumnya yaitu usia ibu dan paritas, sedangkan riwayat seksiso sesarea dan kuretase tidak memiliki hubungan dengan kejadian plasenta previa.

Bagi profesi bidang kesehatan perlu meningkatkan upaya preventif dengan deteksi dini saat pemeriksaan kehamilan sehingga dapat mengidentifikasi tandatanda kelainan pada ibu hamil dan bersalin serta mensosialisasikan kepada masyarakat mengenai pengenalan dini plasenta pevia. Bagi peneliti selanjutnya agar mencari faktor-faktor lain yang dapat memengaruhi kejadian plasenta previa seperti tingkat pendidikan, tingkat sosial ekonomi, status nutrisi, riwayat plasenta previa, sehingga dapat diketahui faktor mana yang dominan hubungannya dengan kejadian plasenta previa.

\section{Konflik Kepentingan}

Penulis menyatakan tidak terdapat konflik kepentingan dalam studi ini.

\section{DAFTAR PUSTAKA}

1. Alkema L, Chou D, Hogan D, Zhang S, Moller A-B, Gemmill A, et al. Global, regional, and national levels and trends in maternal mortality between 1990 and 2015 , with scenario-based projections to 2030: a systematic analysis by the UN Maternal Mortality Estimation Inter-Agency Group. Lancet. 2016; 387(10017):462-74.

2. Departemen Kesehatan RI. Pusat Data dan Informasi Profil Kementerian Kesehatan Indonesia 2014. Jakarta Selatan: Departemen Kesehatan RI, 2014.

3. Saifudin AB. Kematian ibu di Indonesia Dapatkah kita mencapai target MDGs 2015. MOGI. 2006;30:3-7.

4. Wardana GA, Karkata MK. Faktor resiko plasenta previa. CDK. 2007;34:229-32.

5. Londok THM, Lengkong RA, Suparman E. Karakteristik perdarahan antepartum dan perdarahan postpartum. eBiomedik. 2013;1(1):614-20.

6. Kemenkes RI. Profil Kesehatan Indo-nesia 2005. Jakarta: Departemen Kesehatan RI, 2007.

7. Adigun TA, Eyelade O. Choice of anaesthetic technique for delivery of pregnancy complicated by placenta previa in Ibadan. OMICS Publishing Group, 2012. DOI: $10.4172 / 2155-6148.1000$ 205

8. Giordano R, Cacciatore A, Ciginini P, Vigna R, Romano M. Antepartum haemorrhage. Journal of Prenatal Medicine. 2010;4(1):12-6.

9. Dutta DC. Textbook of Obstetrics Including Perinatalogy and Contraception. New Delhi: Jaypee The Health Sciences 
Pubhlisher, 2015.

10. Manuaba IAC. Ilmu Kebidanan, Penyakit Kandungan dan KB. Jakarta: EGC, 2012.

11. Mochtar R. Sinopsis Obstetric Fisiologi dan Patologi jilid 1. Jakarta: EGC, 2012.

12. Boyle M. Kedaruratan dalam Persalinan: Buku Saku Bidan. Jakarta: EGC, 2008.

13. Rambei I. Gambaran faktor resiko pada kasus plasenta previa di RSUP Dr.M. Djamil Padang periode Januari 2005-Desember 2006 [Tesis]. Padang: Universitas Andalas; 2008.

14. Metti D. Hubungan umur dan paritas dengan kejadian plasenta previa pada ibu bersalin. Jurnal Keperawatan. 2016; 12(1):112-6.
15. Hartuti N. Hubungan paritas dan umur terhadap kejadian plasenta previa di RSUD Syech Yusuf Gowa tahun 2018. Jurnal Kesehatan Delima Pelamonia. 2018;II(I):24-32.

16. Junita E. Hubungan umur dan paritas dengan kejadian plasenta previa di RSUD Rokan Hulu tahun 2012. Jurnal Maternity and Neonatal. 2013; 1(3):122-132.

17. Cunningham FG, Leveno KJ,.Bloom SL, Dashe JS,, Hoffman BL, Casey BM, et al. Williams Obstetrics (23rd ed). McGraw-Hill Education, 2014; p. 801.

18. Suknikhom W, Tannirandom Y. Previous uterine operation and placenta previa. $\mathbf{J}$ Med Assoc Thai. 2011;94(3):272-7. 